\title{
TR90 Bölgesinde Faaliyet Gösteren İşletmelerin Üretim Maliyetlerinin Rekabet Gücü Üzerindeki Etkisi*
}

\author{
Turan ÖNDEŞ ${ }^{* *}$ \\ Büşra TOSUNOĞLU***
}

\section{ÖZET}

Bu çalışmanın amacı, işletmelerin üretim maliyetlerinin rekabet gücü üzerindeki etkisini belirlemektir. Bu doğrultuda bir model geliştirilmiş ve test edilmiştir. Modelin testi için 3 hipotez oluşturulmuş ve TR90 Bölgesi imalat sektöründe faaliyet gösteren 349 firmaya bir anket uygulanmıştır. Oluşturulan hipotezlerin test edilmesinde yapısal eşitlik modeli kullanılmıştır. Analiz bulgularına göre; direkt ilk madde ve malzeme ile genel üretim maliyetlerinin rekabet gücü üzerinde hemen hemen eşit düzeyde ve negatif yönde bir etki oluşturduğu, direkt işçilik maliyetinin ise negatif yönde ancak diğer üretim maliyetlerine klyasla daha düşük düzeyde bir etkisi olduğu söylenebilir.

Anahtar Kelimeler: Rekabet Gücü, Direkt Illk Madde ve Malzeme Maliyetleri, Direkt Isş̧ilik Maliyetleri, Genel Üretim Maliyetleri, Yapısal Eşitlik Modeli.

JEL Sinıflandırması: M40, M41.

The Effects of Production Costs on Competitiveness in Enterprises: A Practices in TR90 Manufacturing Sector

\section{ABSTRACT}

The purpose of this study is to determine the effects of production costs on competitiveness in enterprises. In this regard, a model has been developed and tested. 3 hypotheses were constituted to test the model and a questionnaire was conducted to 349 firms which are operating in TR90 manufacturing sector. Structural equation model was used to test the hypotheses. According to findings of the analysis, it may be seen that, direct raw materials and supplies costs and general production costs have a negative but nearly equal effect on competiveness while direct labour costs have a negative but rather low effect than other production costs.

Keywords: Competitiveness, Direct Raw Materials and Supplies Costs, Direct Labour Costs, General Production Costs, Structural Equation Modeling.

Jel Classification: M40, M41.

\footnotetext{
* Bu çalışma, Atatürk Üniversitesi Sosyal Bilimler Enstitüsü’nün belirlediği jüri tarafından 19.09.2014 tarihinde kabul edilen "İşletmelerin Üretim Maliyetlerinin Rekabet Gücü Üzerindeki Etkisi: TR90 Bölgesi İmalat Sektöründe Bir Uygulama" isimli doktora tezinden türetilmiştir.

** Prof. Dr. Turan ÖNDEŞ, Atatürk Üniversitesi, İktisadi ve İdari Bilimler Fakültesi, ondesturan@atauni.edu.tr

*** Yrd. Doç. Dr. Büşra TOSUNOĞLU, Gümüşhane Üniversitesi, İktisadi ve İdari Bilimler Fakültesi, busra.tosunoglu@gumushane.edu.tr
} 


\section{GíRiş}

Günümüzde işletmeler, ekonomik sınırların olmadığı dünya pazarlarında ciddi bir rekabet baskısıyla karşı karşıya kalmaktadır. Söz konusu baskılar, işletmelerin sürekli yenilik yapmalarını ve teknolojik değişim ve gelişimlerden haberdar olmalarını bir anlamda zorunlu kılmaktadır (Tanyeri ve Fırat, 2005: 268). Özellikle de yirmi birinci yüzyılın son çeyreğinde ortaya çıkan bilimsel ve teknolojik gelişmelerle birlikte sanayi toplumundan bilgi toplumuna geçilmiş ve bu geçiş beraberinde ekonomik, sosyal, siyasal ve hukuki vb. birçok alanda değişimlere neden olmuştur (Bayri, 2006: 163). Mevcut küresel iş ortamında işletmeler faaliyet gösterdikleri sektördeki diğer işletmelere göre birtakım rekabetçi stratejiler geliştirmek zorundadır (Beheshti, 2004: 377). Bu stratejilere yenilik, kalite, üretim süreçlerinin müşteri beklentilerine uygun bir şekilde düzenlenmesi ve maliyet azaltımı örnek olarak verilebilmektedir.

Rekabet kavramı beraberinde rekabet gücünü de getirmektedir. Müşteri işletmenin üretmiş olduğu ürünlerin alternatifleri karşısında tercih edilebilirliğinin artışı olarak tanımlanan rekabet gücünün verimlilik ve maliyet üstünlüğü gibi iki temel bileşeni bulunmaktadır (Elmacı ve Kurnaz, 2004: 1). Bir işletmenin ya da kar amacı gütmeyen bir kuruluşun etkili bir şekilde yönetilebilmesi için maliyetleri hakkında sahip olunan bilgiler işletmelerin rekabet gücü açısından oldukça önemlidir (Blocker vd., 2002: 8).

Rekabet gücünün öneminin artmasina paralel olarak konu ile ilgili literatür incelendiğinde farklı kriterlerin kullanıldığ pek çok çalışmaya rastlamak mümkündür. Söz konusu çalışmalara kapsamlı bir şekilde literatür araştırması kısmında değinilmiştir. İncelenen literatür araştırması sonucunda üretim maliyetlerinin rekabet gücü üzerindeki etkisini ölçen çalışmaların eksikliği literatürde bir boşluk olarak görülmektedir. Bu durumdan hareketle çalışmanın amacı, işletmelerin üretim maliyetlerinin rekabet gücü üzerindeki etkisini belirlemektir.

Çalı̧̧mada bir bütünlük sağlanabilmesi için ilk olarak kavramsal çerçeve oluşturulmuş ve konu ile ilgili literatüre yer verilmiştir. Çalışmanın son bölümünde ise geliştirilen araştırma modelinin ve modelden çıarılan hipotezlerin test edilmesi sonucu elde edilen bulgular açıklanmaya çalışılmıştır.

\section{LITERATÜR ARAŞTIRMASI}

İşletmelerin sürdürülebilir rekabet gücünün öneminin artmasına paralel olarak konu ile ilgili literatür incelendiğinde farklı kriterlerin kullanıldığ mümkündür. Söz konusu kriterlere bakıldığında; piyasa hacminin, (Fagerberg, 1988; Kim ve Marion 1997; Rubalcaba ve Gago 2001; Esterhuizen, 2006; Tekin ve Zerenler, 2005; Cho, Moon ve Kim, 2008; Mu ve Zhang, 2010), döviz kurunun (Yoshitomi, 1996; Rubalcaba ve Gago, 2001; Zawalinska, 2005; Esterhuizen, 2006; Du Toit, 2010), dışa açıklı̆ıı (Fagerberg, 
1988; Mu ve Zhang, 2010) rekabet gücü üzerindeki etkilerine ilişkin çalışmalar tespit edilmiştir.

Üretim maliyetlerinin rekabet gücü üzerindeki etkisine ilişkin çalışmalara bakıldığında ise genel olarak işçilik maliyetlerinin rekabet gücü üzerindeki etkisini ölçen çalışmalara rastlanmaktadır. Fagerberg (1988), Agrawal (1995), Erdinç (1999), Kotan (2002), Kotan ve Sayan (2003), Kesbiç ve diğerleri (2006), Guerrieri ve Meliciani (2005), Özgener (2005), Eroğlu ve Özdamar (2006), Yalçın (2006), Eşiyok (2007), Du Toit (2009), Çelenk ve Atmaca (2010) ve Güneş, (2012); işçilik maliyetleri ile rekabet gücü arasında negatif bir ilişkinin olduğu ortaya koymuşlardır. İşletmelerin rekabet avantajı elde edebilmeleri için üretim maliyetlerini azaltıcı bir takım yöntemlerin ve politikaların geliştirilmesi ve uygulanması çalışma sonuçlarında ifade edilmektedir. İşçilik maliyetlerinin rekabet gücü üzerindeki negatif etkisini belirten çalışmaların aksine Jorgenson ve Kuroda (1991) ve Yoshitomi (1996)'ye göre; 'işçilik maliyetlerinde meydana gelen artış; yüksek verimlilik ve nitelikli işgücüyle alakalı olup bu durum beraberinde kaynakların kullanımında etkinlik ve verimliliği getirerek rekabet gücünü artırmaktadır. Amendola ve diğerleri (1993) ise piyasadaki iniş çıkışlardan dolayı işçilik maliyetlerinde meydana gelen anlık yükselmelerin rekabet gücünü olumlu etkilediğini ancak piyasadaki dalgalanmaların uzun süreli olmasının söz konusu olumlu etkiyi gittikçe azaltacağını belirtmişlerdir.

Yukarıda genel olarak ifade edilen çalışmalara ilişkin literatür özeti Tablo 1'de sunulmaktadir.

Tablo 1: Üretim Maliyetlerinin Rekabet Gücü Üzerindeki Etkisine İlişkin Literatür Özeti

\begin{tabular}{|c|c|c|c|}
\hline $\begin{array}{c}\text { Yazarlar/ Çalışma } \\
\text { Yılı }\end{array}$ & Sektör & Yöntem & Çalışma sonuçları \\
\hline Fagerberg (1988) & Diş Ticaret & $\begin{array}{l}\text { Panel ve Zaman } \\
\text { Serisi Analizi }\end{array}$ & $\begin{array}{l}\text { İşçilik maliyetlerinde meydana gelen artış } \\
\text { rekabet gücünü olumlu etkilemektedir. }\end{array}$ \\
\hline $\begin{array}{l}\text { Jorgenson ve Kuroda } \\
\text { (1991) }\end{array}$ & İmalat & $\begin{array}{l}\text { Panel Veri } \\
\text { Analizi }\end{array}$ & $\begin{array}{l}\text { İşçilik maliyetlerinde meydana gelen artı̧̧ } \\
\text { rekabet gücünü olumlu etkilemektedir. }\end{array}$ \\
\hline Amendola vd. (1993) & İmalat & $\begin{array}{l}\text { Panel Veri } \\
\text { Analizi }\end{array}$ & 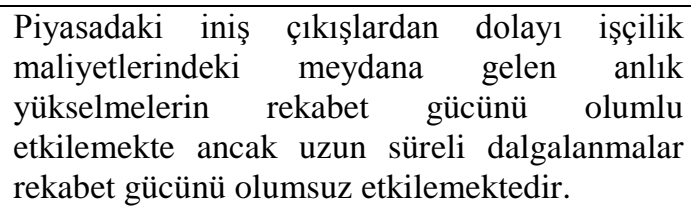 \\
\hline Agrawal (1995) & İmalat & Korelasyon & $\begin{array}{l}\text { İşçilik maliyetleri rekabet gücünü negatif yönde } \\
\text { etkilemektedir. }\end{array}$ \\
\hline Yoshitomi (1996) & İmalat & Korelasyon & $\begin{array}{l}\text { İşçilik maliyetlerinde meydana gelen artış } \\
\text { rekabet gücünü olumlu etkilemektedir. }\end{array}$ \\
\hline Kotan (2002) & İmalat & $\begin{array}{l}\text { Panel Veri } \\
\text { Analizi }\end{array}$ & $\begin{array}{l}\text { İşçilik maliyetleri rekabet gücünü negatif yönde } \\
\text { etkilemektedir. }\end{array}$ \\
\hline Kotan ve Sayan (2003) & Regresyon & Sanayi & $\begin{array}{l}\text { İşçilik maliyetleri rekabet gücünü negatif yönde } \\
\text { etkilemektedir. }\end{array}$ \\
\hline
\end{tabular}




\begin{tabular}{|l|l|l|l|}
\hline Kesbiç vd. (2005) & Tarım & $\begin{array}{l}\text { Panel Veri } \\
\text { Analizi }\end{array}$ & $\begin{array}{l}\text { Üretim maliyetlerinde meydana gelen artış } \\
\text { rekabet gücünü olumsuz etkilemektedir. }\end{array}$ \\
\hline $\begin{array}{l}\text { Guerrieri ve Meliciani } \\
(2005)\end{array}$ & İmalat & $\begin{array}{l}\text { Zaman Serisi } \\
\text { Analizi }\end{array}$ & $\begin{array}{l}\text { İşçilik maliyetleri rekabet gücünü negatif yönde } \\
\text { etkilemektedir }\end{array}$ \\
\hline $\begin{array}{l}\text { Eroğlu ve Özdamar } \\
(2006)\end{array}$ & Beyaz Eşya & Korelasyon & $\begin{array}{l}\text { Üretim maliyetlerinde meydana gelen artış } \\
\text { rekabet gücünü olumsuz etkilemektedir. }\end{array}$ \\
\hline Eşiyok (2007) & Özel İmalat & Regresyon & $\begin{array}{l}\text { İşçilik maliyetleri rekabet gücünü negatif yönde } \\
\text { etkilemektedir. }\end{array}$ \\
\hline Du Toit (2009) & Gida & $\begin{array}{l}\text { Panel Veri } \\
\text { Analizi }\end{array}$ & $\begin{array}{l}\text { Niteliksiz işgücü istihdamı ve düşük } \\
\text { gücünü olumsuz etkilemektedir. }\end{array}$ \\
\hline $\begin{array}{l}\text { Çelenk ve Atmaca } \\
(2010)\end{array}$ & Tekstil & Regresyon & $\begin{array}{l}\text { İşçilik maliyetleri rekabet gücünü negatif yönde } \\
\text { etkilemektedir. }\end{array}$ \\
\hline
\end{tabular}

\section{ARAŞTIRMANIN AMACI, METODOLOJISİ VE BULGULARI}

\subsection{Araştırmanın Amacı}

$\mathrm{Bu}$ araştırmanın amacı, işletmelerin üretim maliyetlerinin (direkt ilk madde ve malzeme, direkt işçilik ve genel üretim) rekabet gücü üzerindeki etkisini gösteren yapısal bir model geliştirmek ve bunu test etmektir.

\subsection{Araştırmanın Metodolojisi}

\subsection{1. Örnekleme Süreci}

Araştırmamızın evreni TR90 Bölgesi (Artvin, Giresun, Gümüşhane, Ordu, Rize ve Trabzon) İmalat Sektöründe faaliyet gösteren işletmelerden oluşmaktadır. Örneklem kütlesinin belirlenmesinde kolayda örnekleme yöntemi kullanılmıştır. Araştırmada TR90 Bölgesinde faaliyet gösteren 360 imalat işletmesine anket uygulanmış, yapılan 360 anketten bazılarının hatalı ve eksik olduğu anlaşılmıştır. Hatalı ve eksik olan anketler çıkarılarak 349 anket dikkate alınmıştır.

\subsubsection{Veri Toplama Yöntem ve Aracı}

Araştırmada verilerin toplanması aşamasında kantitatif araştırma yöntemlerinden biri olan anket yöntemi kullanılmıştır. Araştırmanın anketi TR90 bölgesi imalat sektöründe faaliyet gösteren 349 işletme üzerinde uygulanmıştır. Anket formu işletmelerde yetkili kişilerle yüz yüze görüşme yönteminin yanı sıra, telefon, e-posta ve fax ile ulaştırılarak yapılmıştır. Araştırmanın ilk kısmındaki sorular, işletmelerin sektörel yapılarını belirlemeye yönelik sorulardan oluşmaktadır. İkinci kısımda ise üretim maliyetlerinin rekabet gücü üzerindeki etkilerini belirlemeye yönelik sorulardan oluşmaktadır. Ankette 5'li Likert ölçeği kullanılmış ve ankete katılanlardan, sorulan her bir ifadeye kendi durumlarına uygun cevapları vermeleri istenmiştir. 


\subsubsection{Araştırmanın Modeli ve Değişkenleri}

Direkt ilk madde ve malzeme maliyetlerinin rekabet gücü üzerindeki etkisine yönelik oluşturulan hipotez aşağıdaki gibidir;

H1: Direkt ilk madde ve malzeme maliyetleri rekabet gücü üzerinde negatif bir etkiye sahiptir.

Kotan ve Sayan (2003), Eşiyok (2007) ve Du Toit (2009) direkt işçilik maliyetlerinde meydana gelen artışın rekabet gücü üzerinde olumsuz bir etkiye neden olacağını ifade etmişlerdir.

$\mathrm{Bu}$ varsayımlardan hareketle aşağıdaki geliştirilmiştir;

H2: Direkt işçilik maliyetleri rekabet gücü üzerinde negatif bir etkiye sahiptir.

Genel üretim maliyetlerinin rekabet gücü üzerindeki etkisine yönelik oluşturulan hipotez aşağıdaki gibidir;

H3: Genel Üretim maliyetleri rekabet gücü üzerinde negatif bir etkiye sahiptir.

Araştırmada modelindeki yapılar; direkt ilk madde ve malzeme maliyeti, direkt işçilik maliyeti, genel üretim maliyeti ve rekabet gücüdür. Buradan hareketle araştırmanın hipotezleri şu şekildedir:

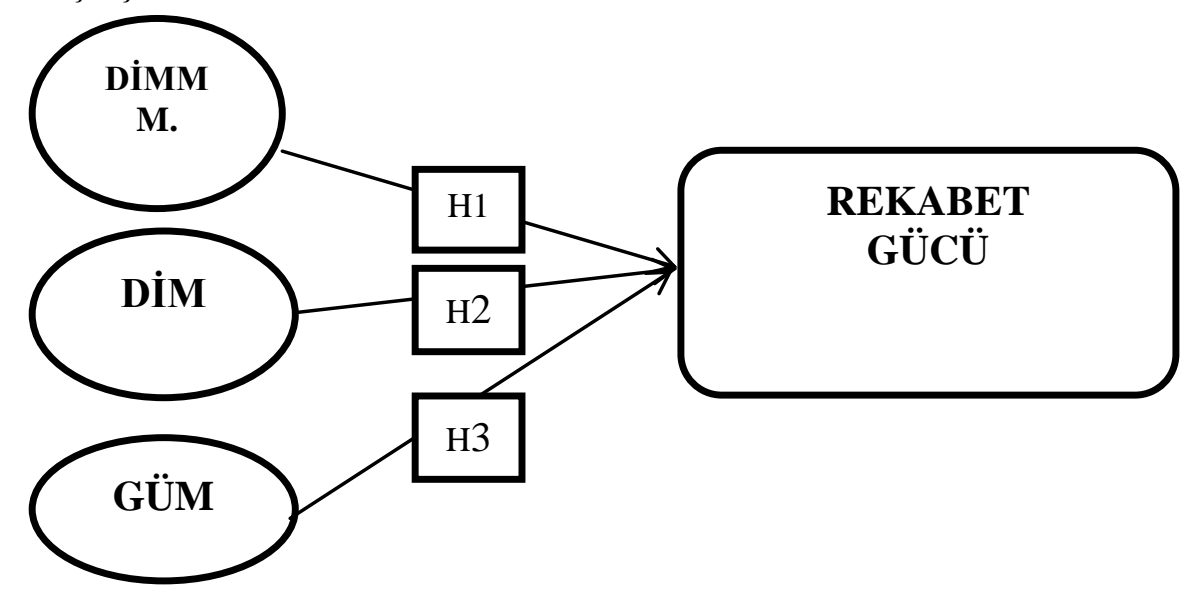

Şekil 1: Direkt İlk Madde ve Malzeme, Direkt İşçilik ve Genel Üretim Maliyetlerinin Rekabet Gücü Üzerindeki Etkilerine Yönelik Yapısal Eşitlik Modeli

\subsubsection{Araştırmanın Analiz Yöntemi}

İşletmelerin üretim maliyetlerinin rekabet gücü üzerindeki etkilerinin test edilmesinde Yapısal Eşitlik Modeli (YEM) kullanılmıştır. Son yıllarda yaygın bir şekilde kullanılan yapısal eşitli modeli, varyans, kovaryans, regresyon ve faktör analizlerinin bileşiminden oluşmaktadır (Yılmaz ve Çelik, 2005: 3). Yapısal eşitlik modeli, gözlenen değişkenler ile örtük değişkenler arasındaki ilişkiler ile korelasyon ilişkilerini içeren modelleri test etmek amacıyla kullanılmaktadır (Tüfekçi ve Tüfekçi, 2006: 173). Regresyon gibi birinci nesil istatistiksel tekniklerle karşılaştırıldığında bu teknik, birden çok bağımlı ve bağımsız 
değişkenler arasındaki doğrusal ve doğrusal olmayan ilişkilerin modellenmesi ile karmaşık bir araştırma problemini tek bir süreçte, sistemli ve kapsamlı bir şekilde ele almaktadır (Anderson ve Gerbing, 1988: 413). Birbirinden farklı ancak birbiriyle ilişkili değişkenlerin aynı anda ele alınmasına imkân veren bu modelin istatistiksel tahmin yapabilme, teorik olarak kavramları temsil edebilme ve ölçme hatalarını dikkate alabilme özelliklerine de sahiptir (Hair vd., 1998: 584-585). Çok değişkenli birçok istatistik yöntemlerin açıklayıcı özellik taşımalarına rağmen yapısal eşitlik modelinin doğrulayıcı bir özellik taşıması hipotez testlerinde bu modelin üstün taraflarını ortaya koymaktadır. Ayrıca diğer çok değişkenli istatistik türleri hata ölçümlerini tayin edemez ve düzeltemezken YEM bütün ölçüm parametrelerinin hemen hepsini işleme dâhil ederek sonuçları bu duruma göre gerçekleştirmektedir (Anderson, 2004). Araştırma kapsamında yapılan tüm analizlerde SPSS 19.0 ve AMOS 20.0 paket programı kullanılmıştır.

\subsection{Araştırmanın Bulguları}

\subsubsection{Araştırmaya Katılan İşletmelerin Sektörel Yapılarına İlişkin Özellikleri}

Tablo 2: Araştırmaya Katılan İşletmelerin Sektörel Yapılarına İlişkin Özellikleri

\begin{tabular}{|c|c|c|}
\hline KURULUŞ YILI & FREKANS & YÜZDE \\
\hline $0-5$ y1l arası & 18 & 5,2 \\
\hline 6-10 yıl arası & 66 & 18,9 \\
\hline 10 yıl ve üzeri & 265 & 75,9 \\
\hline TOPLAM & 349 & 100 \\
\hline \multicolumn{3}{|l|}{ ÇALIŞAN SAYISI } \\
\hline 0-9 kişi & 43 & 12,3 \\
\hline 10-49 kişi & 240 & 68,8 \\
\hline 50-249 kişi & 54 & 15,5 \\
\hline 250 kişi ve üzeri & 12 & 3,4 \\
\hline TOPLAM & 349 & 100 \\
\hline \multicolumn{3}{|l|}{ ORTAKLIK YAPISI } \\
\hline Yerli (\%100) & 345 & 98,9 \\
\hline $\begin{array}{l}\text { Yerli Payı \%50 ve üzeri yerli- } \\
\text { yabancı ortaklı }\end{array}$ & 3 & 0,9 \\
\hline $\begin{array}{l}\text { Yerli Payı \%50'den az yerli- } \\
\text { yabancı ortaklı }\end{array}$ & 1 & 0,2 \\
\hline Yabanc1 & 0 & 0 \\
\hline TOPLAM & 349 & 100 \\
\hline
\end{tabular}


Araştırmaya katılan işletmelerin kuruluş yıllarına göre dağılımlarına bakıldığında \%5,2'si 0-5 yıl arası, \%18,9'u 6-10 yıl arası ve \%75,9'u da 10 yıl ve üzeridir. Araştırmaya katılan işletmelerin çalışan sayılarına bakıldığında ise \%12,3'ü 0-9 kişi, \%68,8'i 10-49 kişi, \%15,5’i 50-249 kişi ve \%3,4'ü ise 250 kişi ve üzeridir. Araştırmaya katılan işletmelerin $\% 98,9$ ’u yerli (\%100), \%,9’u yerli-yabancı (yerli payı \%50 ve üzeri), \%,3'ü ise yerli-yabancı (yerli payı \%50'den az) ortaklık yapısına sahiptir. Tablodaki verilere bakıldığında ortaklık yapılarına göre tamamı yabancı paya sahip işletmelerin olmadığı görülmektedir.

Araştırmaya katılan işletmelerin \%1,4'ü ağaç-orman, çimento ve kağıt , \%1,1'i ambalaj, \%1,7'si cam-seramik, demir-çelik, elektrik-elektronik, \%,6's1 enerji-petrol kimya, \%,3'ü dayanıklı tüketim malzemeleri, \%4,3'ü inşaat malzemeleri, makine, \%2'si maden, \%,9'u metal ve plastik, \%2,9'u otomotiv, \%60,2'si gida-içecek, \%6'si tekstil-konfeksiyon, \%1,4’ü kağıt ve \%6,6’sı ise diğer sektörlerde faaliyet göstermektedir.

\subsection{2. Ölçüm Modeli}

$\mathrm{Bu}$ araştırmada üretim maliyetlerinin rekabet gücü üzerinde etkili olduğu ortaya konulan kavramsal faktörlerin araştırılmasına yönelik olarak, güvenilirlik analizi ve doğrulayıcı faktör analizi yapılmıştır. Güvenilirlik, bir ankette yer alan soruların birbiriyle olan tutarlılığını ölçmenin yanında kullanılan ölçeğin ilgilenilen sorunu ne kadar doğru yansıttığını ifade etmekte ve yapılan her ölçüm için gerekmektedir (Kalaycı, 2005: 405).

Modelde yer alan her bir faktöre ilişkin güvenilirlik analizi yapılarak Tablo 3’te sunulmuştur.

Tablo 3: Araştırmada Yer Alan Ölçeklerin Güvenilirlik Analizi Sonuçlarının Özet Tablosu

\begin{tabular}{|l|c|c|}
\hline \multicolumn{1}{|c|}{ Modelde Yer Alan Ölçekler } & Değişken Sayısı & Alfa Katsayısı \\
\hline Rekabet Gücü & 4 & 0,777 \\
\hline Direkt İlk Madde ve Malzeme Maliyetleri & 5 & 0,724 \\
\hline Direkt İşçilik Maliyetleri & 3 & 0,771 \\
\hline Genel Üretim Maliyetleri & 6 & 0,775 \\
\hline
\end{tabular}

Cronbach Alfa Katsayısı, ağırlıklı standart değişim ortalamasıdır ve bir ölçekteki soruların varyansları toplamının genel varyansa oranlanması sonucu elde edilmektedir. $\mathrm{Bu}$ sayı 0-1 arasında değer almakta ve 1'e ne kadar yaklaşırsa ölçeğin güvenilirliği o kadar yükselmektedir. Ölçeğin $\alpha$ değeri; $\leq \alpha \leq 0.40$ arasında ise ölçek güvenilir değil, $0.40 \leq \alpha \leq$ 0.60 arasında ise ölçeğin güvenilirliği düşük, $0.60 \leq \alpha \leq 0.80$ arasında ise ölçek oldukça güvenilir ve $0.80 \leq \alpha \leq 1.00$ arasında ise ölçek yüksek derecede güvenilir bir ölçek olarak ifade edilmektedir (Kalayc1, 2005: 405). Tablo 3'te yer alan her bir ölçeğe ilişkin güvenirlik analizi sonuçlarına bakıldığında ölçeklerin oldukça güvenilir olduğu söylenebilmektedir. 
Bir testin ölçmek istediği kriteri ölçme derecesi olarak tanımlanan geçerlilik analiziyle ölçekte yer alan sorular ile gerçekte ölçülmek istenen kriteri ölçmesi beklenmektedir (Altunışık vd., 2005: 48). Geçerlilik analizinde, içerik geçerliliği (content validity), eş zamanlı geçerlilik (concurrent), tahminsel geçerlilik (predictive), yüzeysel geçerlilik (face), ve yapı geçerliliği gibi yöntemler kullanılmaktadır. Bir yapıyı ölçmek için kullanılan ölçek sorularının ilgili yapıyı ölçebilme derecesini belirleyen yapı geçerliliğinde genellikle faktör analizi kullanılmaktadır. Araştırmada ölçek geçerliliğinin tespitinin yapılmasında örtük değişken ile her bir örtük değişkeni oluşturan gözlenen değişkenler arasındaki ilişkiyi belirlemek için kullanılan bir analiz yöntemi olarak tanımlanan doğrulayıcı faktör analizi kullanılmıştır (Şimşek, 2007: 7).

Modelde yer alan her bir faktöre ilişkin geçerlilik analizi yapılarak Tablo 4'te sunulmuştur.

Tablo 4: Araştırmada Yer Alan Ölçeklerin Doğrulayıcı Faktör Analizi Sonuçları

\begin{tabular}{|l|c|c|c|c|c|c|c|c|c|}
\hline \multicolumn{1}{|c|}{ Ölçekler } & $\boldsymbol{\chi 2}$ & $\boldsymbol{\chi} \mathbf{2}$ /df & RMSEA & GFI & AGFI & CFI & NFI & TLI & RFI \\
\hline Rekabet Gücü & 2,114 & 2.100 & 0,051 & 0,997 & 0,970 & 0,993 & 0,987 & 0,957 & 0,921 \\
\hline DíMM M. & 9,687 & 1,937 & 0,052 & 0,989 & 0,966 & 0,985 & 0,970 & 0,970 & 0,939 \\
\hline DíM & 17,056 & 2,530 & 0,043 & 0,998 & 0,976 & 0,910 & 0,891 & 0,910 & 0,921 \\
\hline GÜM & 10,524 & 1,169 & 0,022 & 0,990 & 0,976 & 0,993 & 0,958 & 0,989 & 0,930 \\
\hline
\end{tabular}

Yapılan doğrulayıcı faktör analizinin uyum ölçüleri Tablo 4'te görülmektedir. Uyum ölçüleri incelendiğinde $\chi 2$ /df, RMSEA, GFI, AGFI, CFI, NFI, TLI ve RFI değerleri, tavsiye edilen ideal uyum ölçütlerini sağladıkları için doğrulayıcı faktör analizi sonucunda, ele alınan her bir ölçeğe ilişkin en uygun faktör yapısına ulaşıldığg sonucuna varılmaktadır.

\subsubsection{Yapısal Eşitlik Modeli Sonuçları}

Yapısal eşitlik modelinde önceden elde edilen modelin elde edilen veriyi ne kadar iyi açıklayabildiği modelin kabul edilmesi veya reddedilmesi kararının verildiği aşama olarak tanımlanan uyum iyiliği indeksleri ile belirlenmektedir (Information Technology Services, 2004). Modelin tamamının uyum iyiliği testleri sonucunda reddedilmesi, modelde yer alan katsayıların ve parametrelerin önemli olmadığı ve değerlendirilmediği anlamı taşımaktadır (Mels, 2004). Modelin kabul edilmesi durumunda ise uyum iyiliği indeksinde yer alan parametreler, indeks ölçütleri dikkate alınarak yorumlanmaktadır. Uygulamada çok sayıda uyum iyiliği indeksi olmakla birlikte çalışmalarda ancak 5-6 tanesi kullanılabilmektedir (Garson, 2004). Bu çalışmada da en çok kullanılan uyum iyiliği ölçüleri dikkate alınmış ve değerlendirmeler bu indekslere göre Tablo 5 'te yapılmıştır. 
Tablo 5: Araştırma Modelinin Uyum İyiliği Sonuçları

\begin{tabular}{|l|c|}
\hline \multicolumn{1}{|c|}{ Model Uyum İndeksleri } & Model \\
\hline X2 (Ki-Kare) değeri & 218,378 \\
Serbestlik Derecesi & 1,790 \\
GFI (Uyum İyiliği İndeksi) & 0,939 \\
IFI (Artırımlı Uyum İyiliği İndeksi) & 0,929 \\
CFI (Karşılaştırmalı Uyum İyiliği İndeksi) & 0,927 \\
NFI (Normlaşmış Uyum İyiliği İndeksi) & 0,852 \\
RMSEA (Yaklaşım Hatasısının Kök Ortalama Karesi) & 0,048 \\
\hline
\end{tabular}

Ki Kare $\left(\chi^{2}\right)$ değer olarak yüksek ve anlamlı bulunmuştur. $\left(\chi^{2}=218,378, p=0,000\right)$. Ki Kare $\left(\chi^{2}\right)$ değerinin yüksek çıkması serbestlik derecesinin yüksek çıkması (serbestlik derecesi $=122$ ) ile ilişkili olduğu için Ki Kare değerinin serbestlik derecesi etkisinden arındırılmış hali olan $\chi^{2 / d f \leq 2}$ değeri değerlendirilmiştir. $\chi^{2 / d f \leq 2}$ değeri 1,790 çıkmış olup 5'ten küçüktür. Sonuç olarak model, indeks bakımından iyi uyum göstermiştir. GFI (Uyum İyiliği İndeksi), varsayılan modelce hesaplanan gözlenen değişkenler arasındaki genel kovaryans miktarını gösterir. Regresyon analizindeki $\mathrm{R}^{2}$ gibi açıklanabilir. Aralarındaki fark $\mathrm{R}^{2}$ (determinasyon katsayısı) hata varyansıyla ilgili iken GFI gözlenen kovaryans yüzdesiyle ilgilidir. GFI değeri, 0 ile 1 arasında değişir. GFI'nın 0.90'1 aşması, modelin çok iyi olduğu anlamı taşımaktadır. Tablo 3.40’da görüldüğü gibi, model için bu değer 0,939'dur. Model için GFI değerleri de ideal uyum içerisindedir. CFI (Karşılaştırmalı Uyum İyiliği İndeksi), mevcut modelin uyumu ile gizil değişsenler arası korelâsyonu ve kovaryansı yok sayan H0 hipotez modelinin uyumunu karşılaştırmaktadır. CFI'nın kabul edilebilmesi için 0.90'ın üzerinde bir değer alması gerekir (Demerouti, 2004). CFI değeri 0,927 olarak hesaplanmış ve bu değer ideal uyum içerisindedir. IFI indeksi geniş değişkenlerin yarattığı problemlere çözüm bulmak amaciyla ortaya konulmakta ve bu indeksin 0.90'1n üzerinde olması arzu edilmektedir. IFI değeri 0,929'dur. RMSEA'nın (Yaklaşım Hatasının Kök Ortalama Karesi) modelin uygun olabilmesi için 0.05 veya daha düşük bir değer alması gereklidir. Araştırma modelindeki RMSEA, 0,048'dir. NFI (Normlaşmış Uyum İyiliği İndeksi), varsayılan modelin temel ya da H0 hipoteziyle olan uygunluğunu araştırarak, varsayılan modelin kullanılmasıyla iyileşen uygunluk miktarını belirlemektedir. Bulunan değerin 0.90 üzerinde olması gerekmektedir. $\mathrm{Bu}$ değer 1'e ne kadar yaklaşırsa daha fazla uyum iyiliği göstermektedir.

Yukarıda açıklanan uyum iyiliği indekslerine bakıldığında modelin bir bütün olarak yüksek derecede uyum sağladığı görülmektedir. Şekil 2, araştırma modeli sonucunun AMOS program çıktısını göstermektedir. 


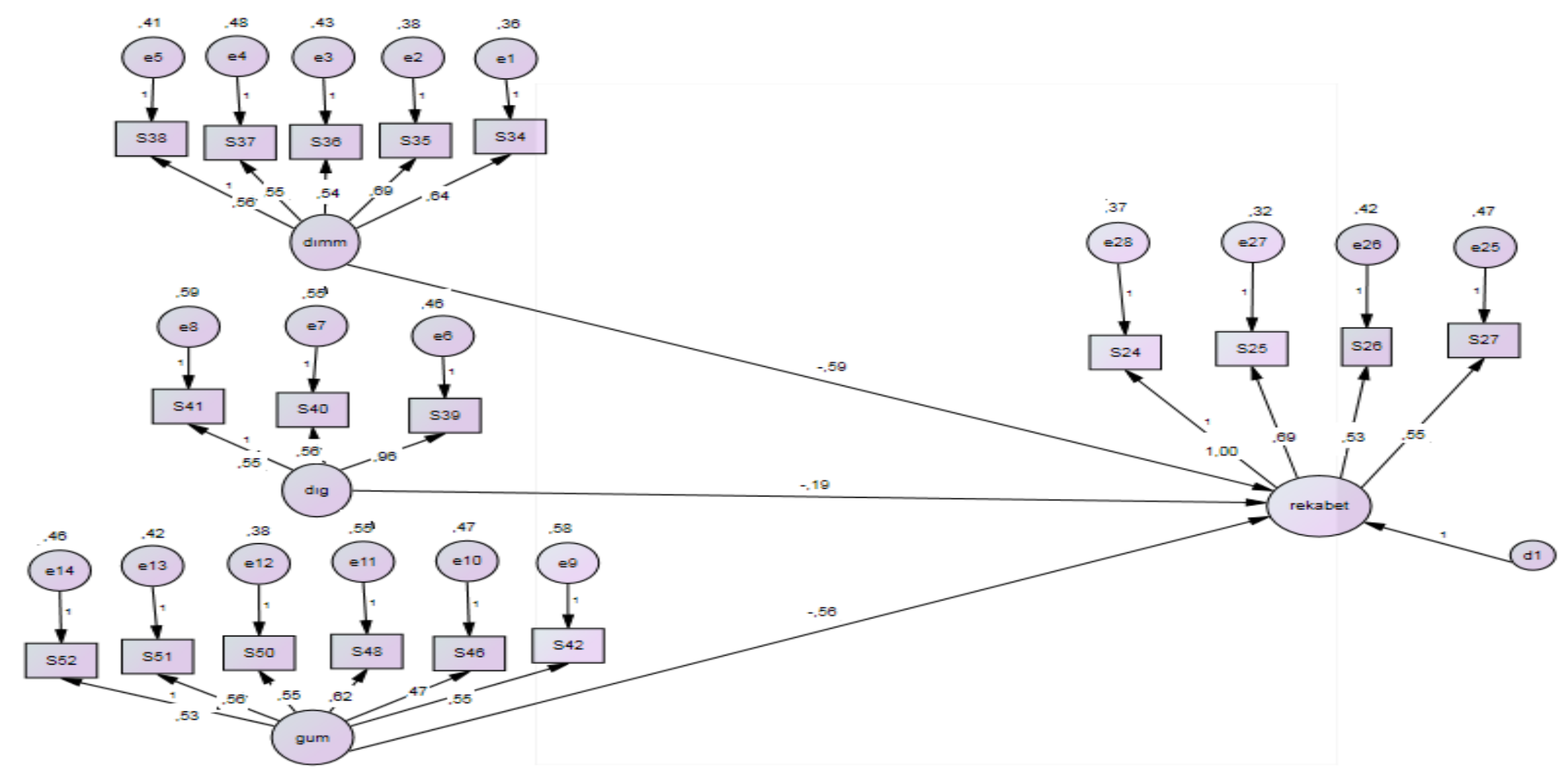

Şekil 2. Araştırma Modeli Testinin AMOS Çıktısı 
Yapısal modelde bağımsız değişken durumunda olan gizil değişkenlere dışsal gizil değişken, bağımlı değişken konumunda olan gizil değişkenlere ise içsel gizil değişken denilmektedir (Demerouti, 2004). Şekil 2'de görüldüğü gibi bu yapısal modelin içinde 4 adet gizil değişken bulunmaktadır. Bunlardan rekabet gücü içsel gizil değişkenleri, direkt ilk madde ve malzeme, direkt işçilik ve genel üretim maliyetleri ise dişsal gizil değişkenleri oluşturmaktadir.

Yapısal model içindeki standart olmayan yükler, çoklu regresyon içindeki regresyon ağırlıklarına karşılık gelmekte ve farklı modeller arası karşılaştırma yapmamıza imkân sağlamaktadır. Standart yükler ise ilişkilerin etki gücünü göstermektedir. Bu yükler en çok 1 değeri alırken en düşük 0 değeri almaktadır (Hair vd., 1998: 614). Tablo 6’da standart ve standart olmayan yükler ile hipotezlerin değerlendirilmesinde kullanılacak değerler yer almaktadır. Tablo 6'da ayrıca ilişkilerin anlamlı olup olamadıkları ve istenilen yönde olup olmadıkları da değerlendirilmiştir. Bu değerlendirmede AMOS programının her bir ilişki için ortaya koyduğu $\mathrm{p}$ değerlerinden faydalanılarak $\mathrm{p}<0,05$ düzeyinde 0,05 'ten küçük olan $\mathrm{p}$ değerleri anlamlı olarak değerlendirilmiştir.

Tablo 6: Araştırma Modelindeki Hipotez Test Sonuçları

\begin{tabular}{|l|c|c|c|c|c|c|}
\hline \multicolumn{1}{|c|}{$\begin{array}{c}\text { Modeldeki Yapısal } \\
\text { İlişkiler }\end{array}$} & $\begin{array}{c}\text { Standardize } \\
\text { Olmayan } \\
\text { Yükler }\end{array}$ & $\begin{array}{c}\text { Standardize } \\
\text { (Regresyon) } \\
\text { Yükler }\end{array}$ & $\begin{array}{c}\text { Standart } \\
\text { Hata }\end{array}$ & $\begin{array}{c}\text { Kritik } \\
\text { Değerler }\end{array}$ & P Değerleri & Hipotez Sonucu \\
\hline Rekabet Gücü Faktörünü Etkileyen Değişkenler $\left(\mathrm{R}^{2}=0,79\right)$ & & & \\
\hline $\begin{array}{l}\text { H1: Rekabet Gücü- } \\
\text { DİMM M. }\end{array}$ & $-0,292$ & $-0,591$ & 0,065 & $-4,520$ & 0,000 & KABUL \\
\hline $\begin{array}{l}\text { H2: Rekabet Gücü- } \\
\text { DİM }\end{array}$ & $-0,165$ & $-0,195$ & 0,059 & $-2,804$ & 0,005 & KABUL \\
\hline $\begin{array}{l}\text { H3: Rekabet Gücü- } \\
\text { GÜM }\end{array}$ & $-0,289$ & $-0,560$ & 0,067 & $-4,298$ & 0,000 & KABUL \\
\hline
\end{tabular}

\section{SONUÇ}

İşletmelerin faaliyetlerini sürekli olarak etkileyen en önemli güçlerden birisi rekabettir. $\mathrm{Bu}$ güce sahip olamayan işletmelerin varlıklarını uzun süreli koruyamadıkları söylenebilmektedir. Dünya piyasasında artan küreselleşme ve teknolojik gelişmeler, ülkelerin ticari sınırlarını genişletmiş ve işletmelerin rekabet koşullarını değiştirmiştir. Ülkelerarası ticari sınırların ortadan kalkması işletmelere farklı ülkelerde faaliyette bulunan işletmelerle işbirliği yapmayı veya rekabet edebilmeyi öğretmiştir. Önceleri düşük kaliteli ve yüksek maliyetle üretim yapan işletmeler küreselleşme süreciyle birlikte uluslararası rekabette başarılı olabilmek için kendilerini geliştirerek daha kaliteli ve düşük maliyetli ürünleri piyasa sunmaktadır. Söz konusu değişimle birlikte işletmelerin üretim sistemlerindeki "ne üretirsem satarım" anlayışı geçerliliğini kaybetmiş yerini müşteri isteklerini dikkate alan bir üretim 
sistemi almıştır. Bu doğrultuda çalışmanın amacı işletmelerin üretim maliyetlerinin rekabet gücü üzerindeki etkisini belirlemeye yöneliktir. Araştırmada ileri sürülen model testi sonuçlarına göre uyum iyiliği indekslerine bakıldığında model bir bütün olarak elde edilen verilere orta derecede uyum sağlamıştır. Model içerisinde öngörülen 3 tane hipotez yer almaktadır. Bu hipotezlerin regresyon katsayıları, $P$ değerleri $(p<0,05)$ ve $t$ değerleri $(t \geq 1,65)$ değerlendirilmesi sonucunda da şu sonuçlar elde edilmiştir;

H1 hipotezi, $-0,591$ regresyon katsayısı ve $p=0,000$ değeri ile kabul edilmiştir. Bunun anlamı direkt ilk madde ve malzeme maliyetleri rekabet gücünü olumsuz etkilemektedir. Direkt ilk madde ve malzeme maliyetlerinde oluşan bir birimlik bir artış işletmelerin rekabet gücünü \%59,1 oranında azaltmaktadır. H2 hipotezi, $-0,195$ regresyon katsayıs1 ve $p=0,005$ değeri ile kabul edilmiştir. Bunun anlamı direkt işçilik maliyetleri rekabet gücünü olumsuz etkilemektedir. Direkt işçilik maliyetlerinde oluşan bir birimlik bir artış işletmelerin rekabet gücünü \%19,5 oranında azaltmaktadır. Araştırma bulguları Kotan (2002), Wang (2002), Kotan ve Sayan (2003), Guerrieri ve Meliciani (2005), Baldemir ve Doğan (2005), Esterhuizen, (2006), Kesbiç, Eroğlu ve Özdamar (2006), Eşiyok (2007), Du Toit (2010), Karagöz ve Şen (2010)'in yapmış oldukları çalışmalarla benzerlik göstermektedir. Araştırma bulguları yukarıda belirtilen çalışmalarla benzerlik gösterse de Fagerberg (1988), Jorgenson ve Kuroda (1991), Amendola, Dosi ve Papagni (1993), Agrawal (1995) ve Yoshimoto (1996)'nin çalışma sonuçlarıyla çelişmektedir. H3 hipotezi, -0,560 regresyon katsayısı ve $p$ $=0,000$ değeri ile kabul edilmiştir. Bunun anlamı genel üretim maliyetleri rekabet gücünü olumsuz etkilemektedir. Genel üretim maliyetlerinde oluşan bir birimlik bir artış işletmelerin rekabet gücünü \%56 oranında azaltmaktadır.

Analiz sonuçlarına göre direkt ilk madde ve malzeme maliyetleri, rekabet gücünü önemli oranda etkilemektedir. İşletmeler kaliteden ödün vermeden daha düşük maliyetli hammadde temini noktasında farklı stratejiler geliştirerek rekabet güçlerini artırma yoluna gitmelidir. Ücretlerin üretim maliyetleri içerisinde küçük bir paya sahip olması, düşük verimlilik ve niteliksiz işgücü istihdamı gibi nedenlerden dolayı işgücü maliyetleri rekabet gücünü negatif etkilemektedir. Modern üretim sistemleriyle birlikte işgücü emeğinin yerini makinalar almakta ve bu durum da genel üretim maliyetlerini artırmaktadır. Artan genel üretim maliyetleri de işletmelerin rekabet gücünü olumsuz etkilemektedir.

$\mathrm{Bu}$ çalışmada işletmelerin sadece üretim maliyetlerinin rekabet gücü üzerindeki etkisi değerlendirilmiştir. Bununla birlikte gelecek çalışmalarda işletmelerin faaliyetleri esnasında katlanmış oldukları giderleri oluşturan araştırma geliştirme, pazarlama satış dağıtım ve genel yönetim giderlerinin rekabet gücü üzerindeki etkileri de araştırılabilir. Ayrıca çalışma sonuçlarından hareketle ileri imalat teknolojilerinin rekabet gücü üzerindeki etkileri de gelecek çalışmalarda incelenebilir. Araştırma sadece TR90 Bölgesi imalat sektöründe faaliyet gösteren işletmeleri dikkate almıştır. $\mathrm{Bu}$ araştırma diğer sektörlerde de uygulanıp hem sektörlere arasında karşılaştırma yapılması fırsatı sağlanabilir hem de genel bir değerlendirme yapılabilme şansı doğurabilir. 


\section{KAYNAKLAR}

Agrawal, Nisha (1995), “Labour Market Policies and International Competitiveness”, The World Bank Office of The Vice President, pp. 1-72.

Altunışık, Remzi- Coşkun, Recai- Bayraktaroğlu, Serkan- Yıldırım, Engin (2005), Sosyal Bilimlerde Araştırma Yöntemleri SPSS Uygulamalı, (4. Bask1), Sakarya Kitabevi, Sakarya.

Amendola, Giovanni- Dosi, Giovanni- Papagni, Erasmo (1993), “The Dynamics of International Competitiveness”, Weltwirtschaftliches Archiv, Vol. 129, No. 3, pp. 451471.

Anderson, Joel G. (2004), “The Basic of Structural Equation Model”, http://web.isc..purdue.edu/janders1/Soc681/Soc\%20681\%20Basic\%20of\%20Structura 1\%20Equation\%20Modeling\%20202002.pptrişim (13.08.2014)

Anderson, James- Gerbing, David W. (1998), "Structural Equation Modeling in Practice: A Review and Recommended Two-Step Approach”, Psychological Bulletin, No. 103, pp. 411-423.

Bayri, Osman (2006), "Rekabet Stratejileri Açısından Maliyet-Hacim Analizleri”, Muhasebe ve Finansman Dergisi, Sayı 30, ss. 163-172.

Beheshti, Hooshang M. (2004), "Gaininig and Sustaining Competitive Advantage with Activity Based Cost Management System”, Industrial Management \& Data System, Vol. 104, No. 5, pp. 377-383.

Blocker, Edward- Chen, Kung H.-Lin, Thomas W. (2002), Cost Management, A Strategic Emphasis. Boston: Mc Graw Hill.

Cho, Dong, Sung- Moon, Hwy Chang- Kim, Min Young (2008), “Characterizing International Competitiveness in International Business Research: A MASI Approach to National Competitiveness”, Research in International Business and Finance, No. 22, pp. 175-192.

Çelenk, Hakan- Atmaca, Metin (2010), "Esnek Çalışmanın İşgücü Maliyetlerine ve Rekabet Gücüne Etkisi: Tekstil Sektöründe Bir Uygulama”. Yönetim Bilimleri Dergisi, Cilt 8, Say1 2, ss. 187-202.

Demerouti, Evangelia (2004), “Structural Equation Modeling”, http://www.dmst.Aueb.gr/gr2/diafora2/Prosopiko2/visitors_ppts/Demerouti1.ppt (28.07. 2014).

Du Toit, Justin Philip (2009), "Factors Influencing the Long-Term Competitiveness of Selected Commercial Milk Producers in East Griqualand, South Africa”, (Postgraduate Thesis), University of KwaZulu-Natal Agribusiness Faculty of Science and Agriculture, Pietermaritzburg. 
Elmac1, Orhan- Kurnaz, Niyazi (2004), "Sürdürülebilir Rekabet Gücüne Yönelik Vizyon Arayışlarında Faaliyet Tabanlı Maliyet (FTM) Yaklaşımı”, http://www.muhasebetr.com/makaleler/014/ (11. 12. 2014).

Erdinç, Zeynep (1999), “Küreselleşmenin İstihdama Etkileri”. Dumlupınar Üniversitesi Sosyal Bilimler Dergisi, Sayı 3, ss. 111-120.

Eroğlu, Ömer- Özdamar, Gökhan (2006), “Türk İmalat Sanayiinin Rekabet Gücü ve Beyaz Eşya Sektörü Üzerine Bir İnceleme”, Akdeniz İ.İ.B.F. Dergisi, Sayı 11, ss. 85-104.

Esterhuizen, Dirk- Rooyen, Johan Van- Haese, Luc (2006), "An Evaluation of the Competitiveness of the Agribusiness Sector in South Africa”, Competition Forum, Vol. 4, No. 1, pp. 72-85.

Eşiyok, Ali (2007), "Türkiye Ekonomisinin Rekabet Gücündeki Gelişmeler ve Faktör Kullanım Yoğunluklarına Göre Dış Ticaretin Yapısı", Finans Politik \& Ekonomik Yorumlar, Cilt 44, Say1 514, ss. 15-36.

Fagerberg, Jan (1988), “International Competitiveness”, The Economic Journal, Vol. 98, No. 391, pp. 355-374.

Garson, David (2004), "Structural Equation Modeling”, http://www2.chass.ncsu .edu/garson/pa765/structur.htm. (15.03.2014).

Guerrieri, Paolo- Meliciani, Valentina (2005), “Technology and International Competitiveness: The Interdependence Between Manufacturing and Producer Services”, Structural Change and Economic Dynamics, Vol. 16, No. 4, pp. 489-502.

Güneş, Sevcan (2012), "Rekabet Düzeyi İle Büyüme Arasındaki İlişki: Panel Analizi” Finansal Araştırmalar ve Çalışmalar Dergisi, Cilt 3, Sayı 7, ss. 43-54.

Hair, Joseph F.- Ronald, Tatham L.- Rolph Anderson E.- William, Black (1998), Multivariate Data Analysis, Prentice Hall, Upper Saddle River., 5th Edition, New Jersey.

Information Technology Services (2004), "Structural Equation Modeling Using AMOS: An Introduction”, http://www.utexas.edu/its/rc/tutorials/stat/amos/. (13.08. 2014).

Jorgenson, Dale W- Kuroda, Masahiro (1991). "Productivity and International Competitiveness in Japan and the United States, 1960-1985”, NBER Discussion Papers, W.P., No. 8442, pp. 29-57.

Kalaycı, Şeref (2005), SPSS Uygulamalı Çok Değişkenli İstatistik Değişkenleri, Asil Yayın Dağıtım, 2. Baskı, İstanbul.

Karagöz, Kadir- Şen, Ali (2010), “Döviz Kuru Rejimi- Ticari Rekabet Gücü İlişkisi: Türkiye İçin Ampirik Bir Analiz”, Akademik Bakış Dergisi, Sayı 21, ss. 1-12.

Kesbiç, Yenal C.- Baldemir, Ercan- Doğan, Sibel (2006), "Rekabet Gücü Ölçümü ve Önemi: Türk Tarım Sektörü İçin Bir Analiz", VII. Ulusal Ekonometri ve İstatistik Sempozyumu, İstanbul. 
$\overline{\text { Kim, Donghwan- Marion, Bruce W. (1997), “Domestic Market Structure and Performance in }}$ Global Markets: Theory and Empirical Evidence from U.S. Food Manufacturing Industries”, Review of Industrial Organization, No. 12, pp. 335-354.

Kotan, Zelal (2002), “Uluslararası Rekabet Gücü Göstergeleri Türkiye Örneği”, Türkiye Cumhuriyeti Merkez Bankası Araştırma Genel Müdürlüğü.

Kotan, Zelal- Sayan, Serdar (2003), “Türk İhraç Ürünlerinin AB Pazarında Güney Doğu Asya Ülkelerine Karşı Rekabet Gücünün Analizi: 1990-99”, Ekonomik Yaklaşım Dergisi, Cilt 14, Sayı 44-46, ss. 1-19.

Mels, Gerhard (2004), “Getting Started With The Student Edition of Lisrel 8.53 For Windows”, http://www.psikolojiktestler.hacettepe.edu.tr/l. doc. (13.08.2014)

Mu, Quan- Zang, Shigiu (2010), "Factor Analysis of International Competitiveness of the Iron and Steel Industry in China”, The Sixteenth Annual International Sustainable Development Research Conference, Hong Kong.

Özgener, Şevki (2005), “Çalışma Hayatında Esnekliğin İşletme Verimliliği Üzerine Etkileri: Karşılaştırmalı Bir Çalışma”, Amme İdaresi Dergisi, Cilt 38, Sayı 3, ss. 51-79.

Rubalcaba, Luis- Gago, David (2001), "Relationship Between Services and Competitiveness: The Case of Spanish Trade”, The Case of Spanish Trade The Service Industries Journal, Vol. 21, No. 1, pp. 35-62.

Şimşek, Ömer Faruk (2007), Yapısal Eşitlik Modellemesine Giriş: Temel İlkeler ve LISREL Uygulamaları, Ekinoks Yayınevi, Ankara.

Tanyeri, Mustafa- Fırat, Aytekin (2005), "Rekabet Değişkeni Olarak Dış Kaynak Kullanımı”, Dokuz Eylül Üniversitesi, Sosyal Bilimler Enstitüsü, Cilt 7, Sayı 3, ss. 268-279.

Tekin, Mahmut- Zerenler, Muammer (2005), “Konya Otomotiv Yan Sanayiinin Rekabet Gücü Hakkında Bir Araştırma”, V. Ulusal Üretim Araştırmaları Sempozyumu, İstanbul.

Tüfekçi, Nezihe- Tüfekçi, Ömer Kürşad (2006), "Bankacılık Sektöründe Farklı Olma Üstünlüğünün ve Müşteri Sadakatinin Yarattığı Değer: Isparta İl'inde Bir Uygulama”, Süleyman Demirel Üniversitesi Sosyal Bilimler Enstitüsü Dergisi, Cilt 2, Say1 4, ss. 170-183.

Wang, Ru Zhu (2002), "Determinants of International Competitiveness-An Empirical Study of The Progress, Difficulties, Models”, Statistical Research, No. 4, pp. 20-24.

Yalçın, Selçuk (2006), "Rekabet Avantajı Sağlamada Stratejik Maliyet Yönetiminin Muhasebe Uygulamalarıyla İlişkileri”, Dumlupınar Üniversitesi Sosyal Bilimler Dergisi, Sayı 15, ss. 15-34.

Yılmaz, Veysel- Çelik, H. Eray (2005), "Bankacılık Sektöründe Müşteri Memnuniyeti ve Bankaya Bağlılık Arasındaki İlişkinin Yapısal Eşitlik Modeliyle Araştırılması”, VII. Ulusal Ekonometri ve İstatistik Sempozyumu, İstanbul. 
Yoshitomi, Masaru (1996), "On The Changing International Competitiveness of Japanese Manifacturing Since 1985”, Oxford Review of Economic Policy, Vol. 12, No. 3, pp. 61-73.

Zawalinska, Katarzyna (2005), "Changes in Competitiveness of Farm Sector in Candidate Countries Prior to the EU Accession: The Case of Poland”, 2005 International Congress, Denmark. 